\section{Striking the balance between too little and too much physical activity}

\author{
Hilde Moseby Berge, ${ }^{1}$ Ben Clarsen ${ }^{2}$
}

It should be pretty obvious; movement is good, sitting still is bad. However, physical activity rates continue to fall across the world. ${ }^{1}$ As sports and exercise medicine practitioners, we could be seen as frontline soldiers in the fight against inactivity. As such, we need to be well armed with knowledge about the consequences of inactivity, about what can be done to combat it and about who we should be targeting. These themes are all covered in this issue which shines the spotlight on an increasingly researched topic in Norway-the relationship between physical activity and health.

We start with a study documenting the declining activity levels of British school children as they age from 10 to 14 years (see page 730). We hope their increased sedentary time is not spent in front of a computer or watching $\mathrm{TV}$, because in their huge meta-analysis, Zhai et al show that these behaviours are associated with an increased risk of depression (see page 705).

Cardiovascular consequences of sedentary lifestyle have been assessed in two large Norwegian population studies, the HUNT3 study and the Oslo II study, discussed in E Berge's editorial (see page 702). In one paper from each study, both Chau et al (see page 737) and Holme and Anderssen (see page 743) highlight the association between sedentary behaviour and mortality risk. The latter study draws a fascinating parallel-showing that to reduce mortality risk, increasing physical activity levels is as important as quitting

\footnotetext{
${ }^{1}$ The Norwegian Olympic Training Center (Olympiatoppen), Oslo, Norway; ${ }^{2}$ Oslo Sports Trauma Research Center, Oslo, Norway

Correspondence to Dr Hilde Moseby Berge, The Norwegian Olympic Training Center (Olympiatoppen), Sogsnveien 228, Oslo 0840, Norway; hilde.moseby. berge@olympiatoppen.no
}

smoking. This may be a turning point, as in Norway (where the number of regular smokers has reduced by $40 \%$ over the past 10 years) the anti-smoking message seems finally to be getting through.

A big step towards this reduction of smoking in Norway is likely to have been the introduction of the Tobacco Act in 2004, which banned smoking in public places. Although it was controversial back then, similar laws now exist in 100 other countries. If national policy has proven to be effective in reducing smoking, what about increasing physical activity? This issue is explored by Fiona Bull et al (see page 749 ) who summarise and contrast the national physical activity promotion strategies of seven European countries, including Norway.

Community-level physical activity interventions, such as outdoor walking groups, also offer a wide range of health benefits. In their meta-analysis, Hanson and Jones (see page 710 ) show that walking groups have high levels of adherence, virtually no adverse effects, and lead to improvements in blood pressure (BP), body fat, body mass index, cholesterol and risk of depression. Time to get your walking shoes on? We think so!

\section{TOO MUCH OF A GOOD THING?}

Although being physically active clearly trumps a sedentary lifestyle, is it a case of the more the better? High-level athletes, such as the Norseman iron-distance triathlete on our front cover, have a greater risk of sudden cardiac death, which are why many choose preparticipation cardiac screening with ECG. However, differentiating between training and not trainingrelated ECG findings can be challenging, so check out the free BMJ Learning resource on how to interpret ECG in athletes (see page 703). The economic consequences of mass cardiac screening are highlighted by
Menafoglio et al (see page 757). In their examinations of elderly athletes one of the most common abnormal findings was systemic hypertension. In a systematic review of BP and hypertension in younger athletes Berge et al (see page 716) saw a trend towards a higher BP in athletes training $\geq 10 \mathrm{~h}$ compared with others. The prognostic significance of hypertension in athletes is interesting, as is the relative right ventricular dysfunction following prolonged exercise. The latter issue is debated in a meta-analysis by Elliot and La Gerche (see page 724).

\section{UPCOMING CONFERENCES}

Great lectures on inactivity, the athlete's heart and the consequences of excessive exercise, together with injury prevention methods such as the IOC's Get Set app (see page 762) are central at this year's combined NIMF and FFI annual conference, which takes place in Trondheim from the 6-8th of November (http://www. imhk2015.com). We also take the opportunity to give advance notice for next year's Scandinavian Congress of Medicine and Science in Sports which will be held in November in the mountains near Oslo (http://www.imhk2016.com, address valid from November 2015). All sessions will be held in English and there will be plenty of time to get active, in the beautiful Norwegian nature and of course on the dancefloor. We hope to see you there!

Twitter Follow Hilde Moseby Berge at @HildeMBerge / Ben Clarsen at @benclarsen

Competing interests None declared.

Provenance and peer review Not commissioned; internally peer reviewed.

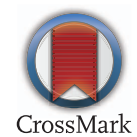

To cite Berge HM, Clarsen B. Br J Sports Med 2015;49:701.

Accepted 1 April 2015

Br J Sports Med 2015;49:701.

doi:10.1136/bjsports-2015-094887

\section{REFERENCE}

1 Halla PC, Andersen LB, Bull FC, et al, Lancet physical Activity Series Working Group. Global physical activity levels: surveillance progress, pitfalls, and prospects. Lancet 2012;380:247-57. 